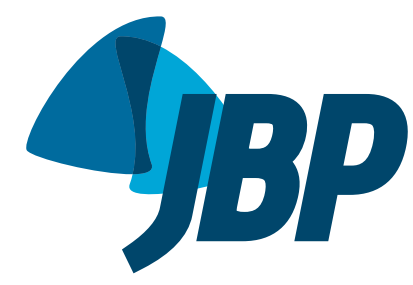

1. Programa de Pós-Graduação em Pesquisa Aplicada à Saúde da Criança e da Mulher, Instituto Nacional de Saúde da Mulher, Criança e Adolescente Fernandes Figueira, Fundação Oswaldo Cruz, Rio de Janeiro (RJ) Brasil.

2. Setor de Fisioterapia Respiratória, Instituto Nacional de Saúde da Mulher, Criança e Adolescente Fernandes Figueira, Fundação Oswaldo Cruz, Rio de Janeiro (RJ) Brasil.

3. Setor de Prova de Função Pulmonar Instituto Nacional de Saúde da Mulher, Criança e Adolescente Fernandes Figueira, Fundação Oswaldo Cruz, Rio de Janeiro (RJ) Brasil.

4. Setor de Fisioterapia Motora, Instituto Nacional de Saúde da Mulher, Criança e Adolescente Fernandes Figueira, Fundação Oswaldo Cruz, Rio de Janeiro (RJ) Brasil.

5. Ambulatório de Doenças Musculares e Neurofisiologia, Instituto de Neurologia Deolindo Couto, Universidade Federa do Rio de Janeiro, Rio de Janeiro (RJ) Brasil.

6. Centro de Genética Médica, Instituto Nacional de Saúde da Mulher, Criança e Adolescente Fernandes Figueira,

Fundação Oswaldo Cruz, Rio de Janeiro (RJ) Brasil.

Submitted: 20 December 2015 Accepted: 12 September 2016

Study carried out at the Centro de Genética Médica, Instituto Nacional de Saúde da Mulher, Criança e Adolescente Fernandes Figueira, Fundação Oswaldo Cruz, Rio de Janeiro (RJ) Brasil.

\section{Respiratory manifestations in late-onset Pompe disease: a case series conducted in Brazil}

\author{
Bruna de Souza Sixel ${ }^{1,2}$, Luanda Dias da Silva ${ }^{3}$, Nicolette Celani Cavalcanti ${ }^{4}$, \\ Glória Maria Cardoso de Andrade Penque ${ }^{5}$, Sandra Lisboa ${ }^{3}$, \\ Dafne Dain Gandelman Horovitz ${ }^{6}$, Juan Clinton Llerena Jr ${ }^{6}$
}

\begin{abstract}
Objective: To describe respiratory function in a series of patients with late-onset Pompe disease after the definitive diagnosis and before enzyme replacement therapy. Methods: This was a cross-sectional study involving patients with a definitive molecular diagnosis of late-onset Pompe disease. The data analyzed included age at symptom onset; age at definitive diagnosis; type of initial symptoms; time from symptom onset to diagnosis; FVC in the sitting and supine positions; six-minute walk distance; and locomotor ability. Analyses were carried out using frequencies, medians, minimum values, and maximum values. Results: Six patients were included in the study. The median age at symptom onset was 15 years (range, $13-50$ years), and the median age at diagnosis was 39.5 years (range, 10-64 years). The median time from symptom onset to diagnosis was 8 years (range, $0-45$ years). In all cases, the initial manifestation of the disease had been motor weakness. The median FVC in percentage of the predicted value (FVC\%) in the sitting and supine positions was $71.0 \%$ (range, 22.9-104.6\%) and 58.0\% (range, 10.9-106.9\%), respectively. The median $\Delta \mathrm{FVC} \%$ was $24.5 \%$ (range, -4.59 to $52.40 \%$ ). The median six-minute walk distance was $391.7 \mathrm{~m}$ (range, 97-702 m). Conclusions: In this case series, the time from symptom onset to diagnosis was long. Although respiratory signs or symptoms were not the initial manifestations of the disease, $66.7 \%$ of the patients showed reduced FVC\% in the sitting and supine positions at diagnosis.
\end{abstract}

Keywords: Glycogen storage disease type II; Respiratory function tests; Respiratory muscles/pathology.

\section{INTRODUCTION}

Pompe disease (PD), also known as glycogen storage disease type II, is an autosomal recessive hereditary disease caused by mutations in the gene encoding acid alpha-glucosidase, an enzyme that is responsible for the degradation of glycogen, especially at the muscle level.

Data on the incidence of PD are inaccurate, because of the rarity, underdiagnosis, and ethnic distribution of the disease. Data from the United States estimate that its overall incidence is approximately $1: 40,000$. $^{(1)}$ More recent studies that have been conducted in Taiwan and Austria and are based on neonatal screening programs have found higher incidences of approximately $1: 28,000 . \cdot^{(2,3)}$ In
Latin America, only 88 patients had been reported to have the disease by 2012. (4) Data from Brazil are unavailable.

PD is characterized by lysosomal accumulation of glycogen, especially in skeletal and cardiac striated muscles, beginning when acid alpha-glucosidase activity falls below the critical level of $30 \%$. It is classified as classic infantile $\mathrm{PD}$, with symptom onset occurring before the first year of life, accounting for approximately $28 \%$ of all cases; and as late-onset PD, when symptoms appear after that period, including children, youths, and adults. Disease progression in late-onset PD is slower than that in infantile $\mathrm{PD}$, but it is quite variable. Clinical manifestations and disease severity vary according to age at symptom onset, rate of progression, and extent of organ involvement. ${ }^{(5-7)}$

Correspondence to:

Bruna de Souza Sixel. Avenida Rui Barbosa, 716, Flamengo, CEP 22250-020, Rio de Janeiro, RJ, Brasil.

Tel.: 5521 2554-1768. E-mail: brunasixel@iff.fiocruz.br

Financial support: None. 
Until recently, treatment of PD was considered to be only palliative. In 2006, the commercial use of enzyme replacement therapy (ERT) with recombinant human alpha-glucosidase (alglucosidase alpha; Myozyme ${ }^{\circledR}$, Genzyme, Cambridge, MA, USA) was approved in the USA and Europe, and, in 2007, it was also approved in Brazil. The treatment seems to improve respiratory and locomotor functions, as well as survival, in both forms of the disease. ${ }^{(8-10)}$

Muscle weakness is the major symptom in late-onset PD. The paravertebral and proximal lower limb muscles are usually the first to be affected, making it difficult to perform activities of daily living and favoring postural changes. ${ }^{(5)}$ The respiratory consequences of muscle weakness result in restrictive lung disease, with a reduction in vital capacity accompanied by a reduction in $\mathrm{FEV}_{1}$. Initially, breathing is compromised only during sleep, but later on, hypoventilation will occur during the day as well. There is impairment in the cough mechanism and airway clearance, leading to recurrent respiratory infections. Respiratory dysfunction will occur in approximately $75 \%$ of patients. ${ }^{(11)}$ Without treatment, FVC is expected to decrease by $1.0 \%$ to $4.6 \%$ annually. ${ }^{(5,12,13)}$ Respiratory failure is the major cause of death. ${ }^{(14-16)}$

The predominance of diaphragmatic weakness over weakness of other respiratory muscles seems to be a characteristic of PD. ${ }^{(17,18)}$ Therefore, the use of methods capable of assessing the activity of the diaphragm alone can be useful in describing and monitoring the disease. Measurement of transdiaphragmatic pressure is the gold standard for the diagnosis of diaphragmatic dysfunction; however, other simpler methods, such as measurement of FVC in the supine position and difference between sitting and supine FVC have been described and recommended for the clinical follow-up of PD. ${ }^{(16,19-21)}$

At present, little is known about pulmonary manifestations in patients with PD in Brazil, which contributes to the management difficulty in this population. The objective of the present study was to characterize the profile of patients with PD and to describe respiratory function in a series of such patients followed at a referral center for rare diseases in Brazil, after the definitive diagnosis and before ERT.

\section{METHODS}

This was a cross-sectional study involving data obtained from the medical records of patients with a definitive diagnosis of late-onset PD and followed at the Center for Medical Genetics of the Fernandes Figueira National Institute for Women's, Children's, and Adolescents' Health, Fundação Oswaldo Cruz (Fiocruz, Oswaldo Cruz Foundation), located in the city of Rio de Janeiro, Brazil, between 2010 and 2015. Data on clinical history and respiratory function for the period after the diagnosis and prior to the initiation of ERT were analyzed. The exclusion criterion was a lack of data on respiratory function at diagnosis. The study was approved by the local research ethics committee, as part of the International Pompe Disease Registry.

Patient's characteristics and clinical history included data on gender, type of pathogenic mutation, age at symptom onset, type of initial symptoms (motor or respiratory), age at definitive diagnosis, and time from symptom onset to definitive molecular diagnosis. The major initial motor symptoms that are commonly reported and described for PD and that were sought from the medical records included lower limb proximal muscle weakness and/or upper limb proximal muscle weakness; difficulty running, climbing stairs, or walking; frequent falls; trunk muscle weakness; and scoliosis. Respiratory symptoms included orthopnea, dyspnea after exercise, dyspnea at rest, and sleep-disordered breathing. ${ }^{(22)}$ The sample was further characterized on the basis of locomotor function as assessed by the Walton and Gardner-Medwin (WGM) scale ${ }^{(23)}$ and the six-minute walk distance (6MWD). The WGM scale characterizes locomotor ability and has a score ranging from 0 to 10 , with 0 indicating that the patient performs all activities normally and 10 indicating that the patient is completely bedridden. The 6MWD was recorded in meters and as a percentage of the predicted value, using equations from Iwama et al. ${ }^{(24)}$ and Priesnitz et al., ${ }^{(25)}$ for each age group.

The respiratory function variables of interest included FVC, as measured in the sitting and supine positions, and $\mathrm{FEV}_{1}$, both of which are expressed as a percentage of the predicted value (FVC\% and $\mathrm{FEV}_{1} \%$ ); as well as $\mathrm{FEV}_{1} / \mathrm{FVC}$ ratio (in \%) $)^{(26)}$; difference between sitting and supine FVC $(\triangle \mathrm{FVC} \%)$, as calculated using the equation [(sitting FVC - supine FVC)/sitting FVC] $\times 100$; use of (invasive or noninvasive) mechanical ventilatory support; and presence of an artificial airway. Volumes were measured with a MasterScope ${ }^{\circledR}$ spirometer (Jaeger, Hoenberg, Germany), in accordance with the criteria established by the American Thoracic Society, ${ }^{(27)}$ and FVC values $\geq 80 \%$ of predicted were considered normal for the sitting position.

Data were analyzed using descriptive statistics via IBM SPSS Statistics for Windows, version 20.0 (IBM Corp., Armonk, NY, USA). Nominal variables are presented as frequency, and numerical variables are presented as median and range (minimum to maximum).

\section{RESULTS}

During the study period, we identified seven patients with late-onset PD, all of whom were followed at the institution. Only one patient was excluded because he had no spirometry results for the period in question. The individual results are described in Tables 1 and 2 . Of the included patients, four $(66.7 \%)$ were male. All patients were compound heterozygous for the mutation found. The intronic mutation $c-32-13 T>G$, which is known as potentially mild, was present in $100 \%$ of the cases, and the nonsense mutation c.2560C $>T$, which is known as very severe, ${ }^{(28)}$ was present in three (50\%) of the cases. 
The median age at symptom onset was 15 years (range, 13-50 years), and muscle weakness was found as the initial symptom in all patients, except in patient 2, who was asymptomatic at diagnosis. Frequent falls and difficulty climbing stairs, running, or performing vigorous exercise were reported. The median age at diagnosis was 39.5 years (range, 10-63 years), and diagnosis was made in two adolescents and four adults in accordance with the criteria established by the World Health Organization. The median time from first symptoms to confirmation of the diagnosis of PD was 8 years (range, $0-45$ years), ranging from 0 to 2 years for the adolescents and from 4 to 45 years for the adults. All patients were able to walk. The minimum WGM scale score achieved was zero and the maximum WGM scale score achieved was 6 , which indicates walking only with assistance. The median 6MWD was $391.7 \mathrm{~m}$ (range, 97-702 $\mathrm{m}$ and 19-110\% of the predicted value for age).

Taking into account FVC in the sitting position, four patients $(66.7 \%)$ showed respiratory system impairment at diagnosis, with FVC\% $<80 \%$ of predicted and normal $\mathrm{FEV}_{1} / \mathrm{FVC}$ ratio, characterizing restrictive lung disease, as is expected for neuromuscular diseases. Only one patient already used noninvasive mechanical ventilatory support intermittently, being the one who showed the lowest FVC\% in the sitting and supine positions (22.9\% and $10.9 \%$, respectively) and the highest $\triangle \mathrm{FVC} \%$ (52.38\%). None of the patients used invasive ventilatory support or had been tracheostomized. The median FVC\% in the sitting position was 71\% (range, $22.9-104.6 \%$ ), the median FVC\% in the supine position was $58 \%$ (range, $10.9-106.9 \%$ ), the median $\Delta \mathrm{FVC} \%$ was $24.5 \%$ (range, $-4.59 \%$ to $52.4 \%$ ), the median FEV $_{1} \%$ was $70.35 \%$ (range, $27.0-106.8 \%$ ), and the median $\mathrm{FEV}_{1} / \mathrm{FVC}$ ratio (in \%) was $102.4 \%$ (range, 96.3-118.0\%). Stratification by age group showed that only two adolescents had spirometry results within the normal range.

\section{DISCUSSION}

The clinical history characteristics of our patients with PD were similar to those found in the literature. The type of initial symptoms was predominantly motor, the median age at diagnosis was 39.5 years, and the delay between symptom onset and diagnosis was 8 years. Data from Byrne et al., (16) obtained through analysis of the PD patient registry administered by the Genzyme Corporation, revealed a predominance of motor symptoms, a median age at diagnosis of 37.1 years, and a delay in diagnosis of 4 years. The delay in diagnosis was slightly greater in the analysis carried out by Kishnani et al.(22) The median age at symptom onset was lower in our group of patients (15.0 years vs. 28.8 years).

The rarity of PD, the variability of its clinical presentation, its overlap of signs and symptoms with other neuromuscular diseases, and limited access to the health care system often result in a very long time to diagnosis. The delay in diagnosis seems to be greater in older subjects, which indicates improved knowledge of the disease today. ${ }^{(16,22)}$ Taking into account that patients who are younger and less severely affected respond more favorably to administration of ERT, (13) the importance of early diagnosis and early treatment initiation is evident.

Table 1. General description of the patients in the present case series. ${ }^{\text {a }}$

\begin{tabular}{|c|c|c|c|c|c|c|c|c|}
\hline \multirow[t]{2}{*}{ ID } & \multirow[t]{2}{*}{ Gender } & \multirow{2}{*}{$\begin{array}{l}\text { Birth, } \\
\text { year }\end{array}$} & \multicolumn{2}{|c|}{ AGA mutation } & \multirow{2}{*}{$\begin{array}{c}\text { Age at } \\
\text { symptom } \\
\text { onset, } \\
\text { years }\end{array}$} & \multirow{2}{*}{$\begin{array}{l}\text { Type of initial } \\
\text { symptoms }\end{array}$} & \multirow{2}{*}{$\begin{array}{c}\text { Age at } \\
\text { molecular } \\
\text { diagnosis, } \\
\text { years }\end{array}$} & \multirow{2}{*}{$\begin{array}{c}\text { Delay in } \\
\text { diagnosis, } \\
\text { years }\end{array}$} \\
\hline & & & Allele 1 & Allele 2 & & & & \\
\hline 1 & $M$ & 1992 & c. $-32-13 T>G$ & c. $2560 \mathrm{C}>\mathrm{T}$ & 15 & Motor & 17 & 2 \\
\hline 2 & $\mathrm{~F}$ & 2000 & c. $-32-13 T>G$ & c. $2560 \mathrm{C}>\mathrm{T}$ & - & Asymptomatic & 10 & - \\
\hline 3 & $M$ & 1988 & c. $-32-13 T>G$ & c. $2646+2 T>A$ & 13 & Motor & 25 & 10 \\
\hline $4^{*}$ & $M$ & 1958 & c. $-32-13 T>G$ & c. $1912 \mathrm{G}>\mathrm{T}$ & 50 & Motor & 54 & 4 \\
\hline $5^{* *}$ & M & 1954 & c. $-32-13 T>G$ & c. $1912 \mathrm{G}>\mathrm{T}$ & 13 & Motor & 58 & 45 \\
\hline 6 & $\mathrm{~F}$ & 1951 & c. $2560 \mathrm{C}>\mathrm{T}$, & c. $-32-13 T>G$ & 40 & Motor & 63 & 23 \\
\hline
\end{tabular}

ID: identification; F: female; and M: male. *Patients 1 and 2 and patients 4 and 5 were siblings.

Table 2. Functional description of the patients in the present case series.

\begin{tabular}{|cccccccccc} 
ID & $\begin{array}{c}\text { Sitting } \\
\text { FVC, \% of } \\
\text { predicted }\end{array}$ & $\begin{array}{c}\text { Supine } \\
\text { FVC, \% of } \\
\text { predicted }\end{array}$ & AFVC, \% & $\begin{array}{c}\text { FEV }_{1,} \\
\% \text { of } \\
\text { predicted }\end{array}$ & $\begin{array}{c}\text { FEV }_{1} \text { I } \\
\text { FVC, \% of } \\
\text { predicted }\end{array}$ & $\begin{array}{c}\text { Ventilatory } \\
\text { support }\end{array}$ & $\begin{array}{c}\text { WGM } \\
\text { scale score }\end{array}$ & $\begin{array}{c}\text { 6MWD } \\
\text { m of }\end{array}$ & $\begin{array}{c}\text { \% of } \\
\text { predicted }\end{array}$ \\
\hline 1 & 104.6 & 94.4 & 9.72 & 106.8 & 100.7 & No & 0 & 500 & 77 \\
2 & 102.2 & 106.9 & -4.59 & 105.7 & 104 & No & 0 & 495 & 79 \\
3 & 58.5 & 48.4 & 17.31 & 65.7 & 111.6 & No & 1 & 702 & 110 \\
4 & 60.7 & 42.2 & 30.45 & 58.7 & 96.3 & No & 3 & 376 & 64 \\
5 & 22.9 & 10.9 & 52.38 & 27 & 118 & Yes & 6 & 180 & 39 \\
6 & 77 & 45 & 41.63 & 75 & 100 & No & 6 & 97 & 19 \\
\hline
\end{tabular}

ID: identification; $\triangle \mathrm{FVC}$ : difference between sitting and supine FVC; WGM: Walton and Gardner-Medwin; and 6MWD: six-minute walk distance. 
More than 500 mutations have currently been identified, and the expected effects range from very severe to non-pathogenic. ${ }^{(28)}$ The mutation most commonly observed in our group of patients is also the one most commonly reported by other authors. ${ }^{(16,29)}$ However, the phenotypic behavior is not explained exclusively by the genotype found, especially in late-onset disease. Phenotypic differences are present even in members of the same family, including siblings. ${ }^{(29)}$ Patients 1 and 2 and patients 4 and 5, respectively, were siblings with the disease. In both cases, differences were observed in presentation and severity. However, the diagnosis of the younger siblings was facilitated by their family history, enabling a better functional condition at diagnosis. Records show that $32 \%$ of patients with late-onset PD had a sibling with a diagnosis of $\mathrm{PD}^{(16)}$; therefore, we believe that family screening may be useful in identifying asymptomatic patients and may contribute to a better prognosis.

Monitoring of respiratory function in patients with PD is imperative. ${ }^{(6,7,20)}$ In 2013, Ambrosino et al. ${ }^{(21)}$ described basic management of respiratory dysfunction in $\mathrm{PD}$, including periodic evaluations every 3-12 months, depending on the rate of disease progression; monitoring of respiratory signs and symptoms; spirometry in the sitting and supine positions; measurement of MIP; measurement of peak cough flow; blood gas analysis; and, in some cases, polysomnography and swallowing studies. Consensus statements and guidelines for the management of PD also have similar recommendations. ${ }^{(6,7,20,30)}$

The pathophysiology of chronic respiratory failure in neuromuscular diseases includes not only respiratory muscle weakness but also changes in chest wall compliance, central respiratory control, and swallowing, which, in turn, are responsible for Ineffective cough, alveolar hypoventilation, chest deformities, sleep apnea, atelectasis, airway hyperreactivity, and recurrent pneumonia. ${ }^{(31)}$ Unlike other neuromuscular diseases, in which loss of walking ability precedes ventilatory failure, ${ }^{(5,17)}$ in $\mathrm{PD}$, respiratory symptoms may manifest early, being the initial symptom in $8.5 \%$ of cases. ${ }^{(4)}$ Despite our small sample size, the results for locomotor ability and the 6MWD results, when compared against the spirometry results, seem to corroborate the hypothesis that impairment of the respiratory and locomotor systems is heterogeneous. ${ }^{(32)}$ The patient with the greatest 6MWD already showed reduced $\mathrm{FVC} \%$ in the sitting and supine positions and reduced $\triangle \mathrm{FVC} \%$, whereas the patient with the shortest 6MWD did not have the most severe lung disease.

In our study, none of the patients followed had respiratory symptoms as the first manifestation. However, at diagnosis, we observed signs of respiratory system impairment, as identified by reduced FVC\% in the sitting position (FVC $<80 \%$ of predicted), in $66.7 \%$ of them. Despite the absence of respiratory symptoms as the initial manifestation of the disease and the delay between symptom onset and the first spirometry, we cannot rule out the existence of some degree of respiratory impairment in the very early stages of PD, but without ignoring that age and duration of symptomatic disease also seem to contribute to a worsening of functional findings. It is possible that mild respiratory symptoms were present but went unnoticed because they overlapped with motor symptoms that were more prominent. Questioning and standardized description of the signs and symptoms found, especially at the onset of the disease, may facilitate knowledge and follow-up of patients.

Measures of respiratory muscle strength such as MIP and MEP may be highly relevant to identifying the onset of respiratory muscle impairment, given that changes in them may precede volume reduction as identified by vital capacity. Unfortunately, in our group of patients, we found no such data in the medical records of one of the patients, and two were unable to perform acceptable and reproducible maneuvers. Therefore, MIP and MEP measures could not be included in the analysis, and this represents a limitation of the study.

Diaphragmatic weakness is a dysfunction that is characteristic of $P D,(17,18)$ being considered the major cause of disordered breathing during sleep and respiratory failure. ${ }^{(33)}$ Prigent et al., (34) using magnetic stimulation of the phrenic nerve, and Wens et al.,(18) using magnetic resonance imaging, confirmed the predominance of diaphragmatic weakness over weakness of thoracic respiratory muscles in PD. The most accurate method for assessing diaphragmatic function is to measure transdiaphragmatic pressure during maximal respiratory effort or during spontaneous breathing or use bilateral magnetic stimulation of the phrenic nerves. These methods have the disadvantage of being invasive and not being well accepted by patients, especially when they need to be repeated several times, resulting in them rarely being indicated in clinical practice. ${ }^{(35)} \mathrm{A}$ simpler way to assess diaphragmatic weakness is to measure sitting and supine FVC\% and calculate their difference, which correlates strongly with variation in cranio-caudal diameter as observed by magnetic resonance imaging. ${ }^{(18,36)}$ Normal subjects may show a reduction from sitting to supine $\mathrm{FVC} \%$ as high as $10 \%$. $^{(37)}$ Reductions $>25 \%$ characterize diaphragmatic weakness, with a sensitivity of $79 \%$ and a specificity of $90 \%$. ${ }^{(19)}$ In our sample, $66.7 \%$ of the patients showed $\triangle \mathrm{FVC} \%>10 \%$, and $50 \%$ showed $\triangle \mathrm{FVC} \%$ $>25 \%$. This assessment is recommended for the diagnosis and follow-up of patients with PD because it is a potential marker of the severity of the respiratory dysfunction. $A>10 \%$ reduction strengthens the diagnosis of PD. ${ }^{(30)}$ Other methods have also been described for diaphragmatic assessment, including fluoroscopy, ultrasonography, electromyography, and optoelectronic plethysmography ${ }^{(38)}$; however, they are still infrequently used in clinical practice in PD.

The explanation for the predominance of diaphragmatic involvement in respiratory dysfunction remains unclear. Animal model studies suggest that muscle damage is associated with spinal motoneuron pathology, especially phrenic motoneuron pathology, 
and this contributes to a more pronounced deficit in the motor function of the diaphragm. $(17,39,40)$

As respiratory muscle weakness progresses, the use of noninvasive ventilatory support is indicated, helping to control nocturnal hypoventilation and sleep apnea syndrome, as well as acute and chronic respiratory failure. ${ }^{14,21)}$ Only one patient in our case series used this resource. Specific indications regarding when to start using ventilatory support in PD have not been described. The use of recommendations for neuromuscular diseases in general contributes to this process.

Respiratory system involvement was present in $66.7 \%$ of our patient sample, and diaphragmatic dysfunction as characterized by $\Delta \mathrm{FVC} \%>25 \%$ was present in $50 \%$ of our series at diagnosis, suggesting that even if it is not the initial manifestation, respiratory system involvement may occur early in a significant number of cases. Further studies are needed for a better understanding of this involvement, especially of diaphragmatic dysfunction. The sign and symptom profile used by Llerena et al. (7) and Kishnani et al., (22) the recommendations included in the International Pompe Disease Registry, and the respiratory management proposed by Ambrosino et al.(21) may be of great importance in the approach to patients with suspected PD or already diagnosed with PD.

\section{REFERENCES}

1. Martiniuk F, Chen A, Mack A, Arvanitopoulos E, Chen Y, Rom WN et al. Carrier frequency for glycogen storage disease type II in New York and estimates of affected individuals born with the disease. Am J Med Genet. 1998;79(1):69-72. https://doi.org/10.1002/(SICI)10968628(19980827)79:1<69::AID-AJMG16>3.0.CO;2-K

2. Chiang SC, Hwu WL, Lee NC, Hsu LW, Chien YH. Algorithm for Pompe disease newborn screening: results from the Taiwan screening program. Mol Genet Metab. 2012;106(3):281-6. https:// doi.org/10.1016/j.ymgme.2012.04.013

3. Mechtler TP, Stary S, Metz TF, De Jesús VR, Greber-Platzer S Pollak $A$, et al. Neonatal screening for lysosomal storage disorders: feasibility and incidence from a nationwide study in Austria Lancet. 2012;379(9813):335-41. https://doi.org/10.1016/S0140 6736(11)61266-X

4. Kishnani PS, Amartino HM, Lindberg C, Miller TM, Wilson A, Keutzer $\mathrm{J}$; et al. Methods of diagnosis of patients with Pompe disease: Data from the Pompe Registry. Mol Genet Metab. 2014;113(1-2):84-91. https://doi.org/10.1016/j.ymgme.2014.07.014

5. van der Beek NA, de Vries JM, Hagemans ML, Hop WC, Kroos MA Wokke JH, et al. Clinical features and predictors for disease natura progression in adults with Pompe disease: a Nationwide prospective observational study. Orphanet J Rare Dis. 2012;7:88. https://doi. org/10.1186/1750-1172-7-88

6. Kishnani PS, Steiner RD, Bali D, Berger K, Byrne BJ, Case LE Crowley JF, et al. Pompe disease diagnosis and management guideline. Genet Med. 2006;8(5):267-88. https://doi.org/10.1097/01. gim.0000218152.87434.f3

7. Llerena JC Jr, Horovitz DM, Marie SK, Porta G, Giugliani R Rojas MV, et al. The Brazilian consensus on the management of Pompe disease. J Pediatr. 2009;155(4 Suppl):S47-56. https://doi. org/10.1016/j.jpeds.2009.07.006

8. van der Ploeg AT, Clemens PR, Corzo D, Escolar DM, Florence J, Groeneveld GJ, et al. A randomized study of alglucosidase alfa in late-onset Pompe's disease. N Engl J Med. 2010;362(15):1396-1406. https://doi.org/10.1056/NEJMoa0909859

9. Kishnani PS, Corzo D, Leslie ND, Gruskin D, Van der Ploeg A, Clancy $\mathrm{JP}$, et al. Early treatment with alglucosidase alpha prolongs long-term survival of infants with Pompe disease. Pediatr Res. 2009;66(3):32935. https://doi.org/10.1203/PDR.0b013e3181b24e94

10. Güngör D, Kruijshaar ME, Plug I, D'Agostino RB, Hagemans ML, van Doorn PA, et al. Impact of enzyme replacement therapy on survival in adults with Pompe disease: results from a prospective internationa observational study. Orphanet J Rare Dis. 2013;8:49. https://doi. org/10.1186/1750-1172-8-49

11. van der Beek $\mathrm{NA}$, van Capelle $\mathrm{Cl}$, van der Velden-van Etten $\mathrm{KI}$, Hop WC, van den Berg B, Reuser AJ, et al. Rate of progression and predictive factors for pulmonary outcome in children and adults with Pompe disease. Mol Genet Metab. 2011;104(1-2):129-36. https://doi. org/10.1016/j.ymgme.2011.06.012

12. Wokke JH, Escolar DM, Pestronk A, Jaffe KM, Carter GT, van den Berg LH, et al. Clinical features of late-onset Pompe disease: a prospective cohort study. Muscle Nerve. 2008;38(4):1236-45. https:// doi.org/10.1002/mus.21025

13. de Vries JM, van der Beek NA, Hop WC, Karstens FP, Wokke JH, de Visser $M$, et al. Effect of enzyme therapy and prognostic factors in 69 adults with Pompe disease: an open-label single-center study.
Orphanet J Rare Dis. 2012;7:73. https://doi.org/10.1186/1750-1172 7-73

14. Mellies U, Lofaso F. Pompe disease: a neuromuscular disease with respiratory muscle involvement. Respir Med. 2009;103(4):477-84. https://doi.org/10.1016/j.rmed.2008.12.009

15. Güngör D, de Vries JM, Hop WC, Reuser AJ, van Doorn PA, van der Ploeg AT, et al. Survival and associated factors in 268 adults with Pompe disease prior to treatment with enzyme replacement therapy. Orphanet J Rare Dis. 2011;6:34. https://doi.org/10.1186/1750-11726-34

16. Byrne BJ, Kishnani PS, Case LE, Merlini L, Müller-Felber W, Prasad $S$, et al. Pompe disease: design, methodology, and early findings from Pompe Registry. Mol Genet Metab. 2011;103(1):1-11. https:// doi.org/10.1016/j.ymgme.2011.02.004

17. Fuller DD, EIMallah MK, Smith BK, Corti M, Lawson LA, Falk DJ, et al. The respiratory neuromuscular system in Pompe disease. Respir Physiol Neurobiol. 2013;189(2):241-9. https://doi.org/10.1016/j. resp.2013.06.007

18. Wens SC, Ciet P, Perez-Rovira A, Logie K, Salamon E, Wielopolski P, et al. Lung MRI and impairment of diaphragmatic function in Pompe disease. BMC Pulm Med. 2015;15:54. https://doi.org/10.1186/ s12890-015-0058-3

19. Fromageot C, Lofaso F, Annane D, Falaize L, Lejaille M, Clair B, et al. Supine fall in lung volumes in the assessment of diaphragmatic weakness in neuromuscular disorders. Arch Phys Med Rehabil. 2001;82(1):123-8. https://doi.org/10.1053/apmr.2001.18053

20. Cupler EJ, Berger KI, Leshner RT, Wolfe GI, Han JJ, Barohn RJ, et al. Consensus treatment recommendations for late-onset Pompe disease. Muscle Nerve. 2012;45(3):319-33. https://doi.org/10.1002/ mus.22329

21. Ambrosino N, Confalonieri M, Crescimanno G, Vienello A, Vitacca M The role of respiratory management of Pompe disease. Respir Med. 2013;107(8):1124-32. https://doi.org/10.1016/..rmed.2013.03.004

22. Kishnani PS, Amartino HM, Lindberg C, Miller TM, Wilson A, Keutzer J. Timing of diagnosis of patients with Pompe Disease: data from the Pompe Registry. Am J Med Genet A. 2013;161A(10):2431-43. https://doi.org/10.1002/ajmg.a.36110

23. Gardner-Medwin D, Walton JN. The clinical examination of voluntary muscles. In: Walton JN, editor. Disorders of Voluntary Muscles, 3rd ed., Edinburgh: Churchill Livingstone; 1974, p. 517-60.

24. Iwama AM, Andrade GN, Shima P, Tanni SE, Godoy I, Dourado VZ. The six-minute walk test and body weight-walk distance product in health Brazilian subjects. Braz J Med Biol Res. 2009;42(11):1080-5. https://doi.org/10.1590/S0100-879X2009005000032

25. Priesnitz CV, Rodrigues GH, Stumpf Cda S, Viapiana G, Cabral CP Stein RT, et al. Reference value for the 6-min walk test in health children aged 6-12 years. Pediatr Pulmonol. 2009;44(12):1174-9. https://doi.org/10.1002/ppul.21062

26. Knudson RJ, Lebowitz MD, Holberg CJ, Burrows B. Changes in the normal maximal expiratory flow-volume curve with growth and aging. Am Rev Respir Dis. 1983;127(6):725-34

27. Miller MR, Hankinson J, Brusasco V, Burgos F, Casaburi R, Coates A et al. Standardization of spirometry. Eur Respir J. 2005;26(2):319-38. https://doi.org/10.1183/09031936.05.00034805

28. Erasmus MC [homepage on the internet]. Roterdam: Erasmus MC 
c2015 [cited 2015 Dec 12]. Available from: www.pompecenter.n

29. Kross M, Hoogeveen-Westerveld M, van der Ploeg A, Reuser AJ. The genotype-phenotype correlation in Pompe disease. Am J Med Genet C Semin Med Genet. 2012;160C(1):59-68. https://doi. org/10.1002/ajmg.c.31318

30. American Association of Neuromuscular \& Electrodiagnostic Medicine. Diagnostic criteria for late-onset (childhood and adult) Pompe disease. Muscle Nerve. 2009;40(1):149-60. https://doi. org/10.1002/mus.21393

31. Khatwa UA, Dy FJ. Pulmonary Manifestations of Neuromuscular Diseases. Indian J Pediatr. 2015;82(9):841-51. https://doi. org/10.1007/s12098-015-1814-3

32. Pellegrini $N$, Laforet $P$, Orlikowski D, Pellegrini M, Caillaud C, Eymard $B$, et al. Respiratory insufficiency and limb muscle weakness in adults with Pompe's disease. Eur Respir J. 2005;26(6):1024-31. https://doi. org/10.1183/09031936.05.00020005

33. Mellies $U$, Ragette $R$, Schwake $C$, Baethmann $M$, Voit $T$, Teschler $\mathrm{H}$. Sleep-disordered breathing and respiratory failure in acid maltase deficiency. Neurology. 2001;57(7):1290-5. https://doi.org/10.1212/ WNL.57.7.1290

34. Prigent $H$, Orlikowski $D$, Laforêt $P$, Letilly $N$, Falaize $L$, Pellegrini $\mathrm{N}$, et al. Supine volume drop and diaphragmatic function in adults with Pompe disease. Eur Respir J. 2012;39(6):1545-6. https://doi. org/10.1183/09031936.00169011
35. Meric H, Falaize L, Pradon D, Orlikowski D, Prigent H, Lofaso F. 3D analysis of the chest wall motion for monitoring late-onset Pompe disease patients. Neuromuscul Disord. 2016;26(2):146-52. https:// doi.org/10.1016/..nmd.2015.11.003

36. Gaeta M, Musumeci O, Mondello S, Ruggeri $\mathrm{P}$, Montagnese $\mathrm{F}$, Cucinotta $\mathrm{M}$, et al. Clinical and pathophysiological clues of respiratory dysfunction in late-onset Pompe disease: New insights from a comparative study by MRI and respiratory function assessment. Neuromuscul Disord. 2015;25(11):852-8. https://doi.org/10.1016/i. nmd.2015.09.003

37. Allen SM, Hunt B, Green M. Fall in vital capacity with posture. Br J Dis Chest. 1985;79(3):267-71. https://doi.org/10.1016/00070971(85)90047-6

38. Boon AJ, O'Gorman C. Ultrasound in the Assessment of Respiration J Clin Neurophysiol. 2016;33(2):112-9. https://doi.org/10.1097/ WNP.0000000000000240

39. DeRuisseau LR, Fuller DD, Qiu K, DeRuisseau KC, Donnelly WH Jr, Mah C, et al. Neural deficits contribute to respiratory insufficiency in Pompe disease. Proc Natl Acad Sci U S A. 2009;106(23):9419-24. https://doi.org/10.1073/pnas.0902534106

40. Falk DJ, Todd AG, Lee S, Soustek MS, EIMallah MK, Fuller DD, et al. Peripheral nerve and neuromuscular junction pathology in Pompe disease. Hum Mol Genet. 2015;24(3):625-36. https://doi. org/10.1093/hmg/ddu476 